Economics Development Analysis Journal 6(4)(2017)

\title{
Implementasi Peran Program Kemitraan Bumn dengan UMKM Oleh PT Jasa Marga (Persero)
}

\author{
Andi Setiawan ${ }^{1 凶}$
}

Jurusan Ekonomi Pembangunan, Fakultas Ekonomi, Universitas Negeri Semarang

\begin{tabular}{l}
\hline Info Artikel \\
\hline Sejarah Artikel: \\
Diterima Juli 2017 \\
Disetujui September 2017 \\
Dipublikasikan \\
November 2017 \\
\hline Keywords: \\
Partnership Program, credit \\
distribution mechanism, \\
MSMEs performance \\
\hline
\end{tabular}

\begin{abstract}
Abstrak
Penelitian ini adalah penggabungan antara penelitian kualitatif dan penelitian kuantitatif. Lokasi penelitian di lakukan di Kota Semarang. Data yang digunakan dalam penelitian ini meliputi data primer dari hasil angket kepada Pengusaha Mikro Kecil dan Menengah dan wawancara langsung dengan petugas PT Jasa Marga (Persero), Tbk bagian PKBL (Program Kemitraan dan Bina Lingkungan). Hasil penelitian yang telah dilakukan membuktikan bahwa mekanisme program Penyaluran Kredit yang diberikan PT Jasa Marga (Persero), Tbk kepada Usaha Mikro Kecil Menengah dilaksanakan secara utuh sesuai dengan peraturan yang berlaku. Program Penyaluran Kredit telah dilaksanakan dengan berpedoman pada SK Direksi No.230/KPTS/2007, sasaran dari Program Kemitraan ini adalah Usaha Mikro Kecil Menengah (UMKM), efektivitas penyaluran kredit modal bergulir kurang efektif kepada Usaha Mikro Kecil Menengah untuk penjualan bersih rata - rata setiap bulan karena hanya mengalami kenaikan sebesar 64,75\%. Berdasarkan hasil penelitian dapat disimpulkan bahwa implementasi peran program kemitraan yang dilaksanakan oleh PT Jasa Marga (Persero), Tbk cabang Semarang kepada UMKM sebagian besar kurang efektif dalam meningkatkan kinerja UMKM.
\end{abstract}

\begin{abstract}
This research is a merging of qualitative research and quantitative research. The research location is done in Semarang City. The data used in this study include the primary data from the questionnaire results to Micro Small and Medium Entrepreneurs and direct interviews with officials of PT Jasa Marga (Persero), Tbk part PKBL (Partnership and Community Development Program). The results of the research have proved that the mechanism of Credit Disbursement program given by PT Jasa Marga (Persero) Tbk to Micro Small Medium Enterprises is fully implemented in accordance with the prevailing regulations. Credit Disbursement Program has been implemented based on SK Direction No.230 / KPTS / 2007, the target of this Partnership Program is Micro Small Medium Enterprise (UMKM), the effectiveness of disbursing revolving capital credit is less effective for Micro Small Medium Enterprises for average net sales every month as it only experienced an increase of $64.75 \%$. Based on the results of research can be concluded that the implementation of the role of partnership program implemented by PT Jasa Marga (Persero), Tbk Semarang branch to MSMEs most of the less effective to improve the performance of MSMEs.
\end{abstract}

(C) 2017 Universitas Negeri Semarang

\footnotetext{
Alamat korespondensi:

Gedung L2 Lantai 2 FE Unnes

Kampus Sekaran, Gunungpati, Semarang, 50229

E-mail: edaj@mail.unnes.ac.id
} 


\section{PENDAHULUAN}

Perkembangan ekonomi sangat mempengaruhi pertumbuhan ekonomi suatu Negara itu sendiri.Perkembangan tersebut ditujukan pada tahap negara berkembang, sedangkan pertumbuhan ditujukan pada tahap negara maju.Indonesia merupakan negara berkembang, jadi sangat perlu memperhatikan Perkembangan Ekonomi dari berbagai sektor Industri, baik itu Industri besar maupun Industri Kecil.Praktiknya, negara berkembang harus lebih memeperhatikan Usaha Mikro Kecil Menengah (UMKM), karena UMKM memiliki potensi dan kontribusi yang sangat besar bagi perkembangan ekonomi di Indonesia.Vellayati menyatakan mengingat pada bulan Juli tahun 1997, terjadi Krisis Moneter yang melumpuhkan segala aktifitas ekonomi.Banyak perusahaan besar yang gulung tikar, namun hanya pelaku industri kecil yang mampu bertahan dalam krisis moneter.Sebanyak 99\% usaha besar dan konglomerat pailit dan 1\% yang bisa bertahan (dikarenakan, dasar bisnisnya mengandalkan kandungan bahan lokal,bukan impor). Di waktu yang sama, 60\% pelaku UMKM bertahan dan $40 \%$ terkena imbas karena bahan baku mereka sebagian adalah impor.

Pemerintah telah mengarahkan segala potensi yang ada dengan tujuan untuk melancarkan kegiatan produksi guna menggapai kesejahteraan dan taraf hidup yang lebih baik, khususnya bagi masyarakat golongan ekonomi lemah. Upaya pemerintah tersebut adalah untuk mendorong kegiatan dan pertumbuhan ekonomi kerakyatan serta terciptanya pemerataan pembangunan melalui perluasan lapangan kerja, kesempatan berusaha dan pemberdayaan masyarakat Seperti tertuang dalam UndangUndang Dasar Republik Indonesia Tahun 1945 yang menegaskan salah satu tujuan negara adalah memajukan kesejahteraan umum, yang berarti kemakmuran masyarakat yang diutamakan, bukan kemakmuran orang seorang. Keberadaan Usaha Mikro Kecil dan Menengah (UMKM) mencerminkan wujud nyata kehidupan sosial dan ekonomi bagian terbesar dari rakyat Indonesia. Peran Usaha Mikro Kecil dan Menengah (UMKM) yang besar ditunjukkan oleh kontribusinya terhadap produksi nasional, jumlah unit usaha dan pengusaha, serta penyerapan tenaga kerja. Pendekatan holistik terhadap pengembangan UKM sebagian besar bergantung pada pendukung keuangan dan non-keuangan (Ansha, 2017). UMKM pada umumnya berbasis sumber daya ekonomi lokal dan tidak bergantung pada impor, serta hasilnya mampu diekspor karena keunikannya, sehingga pembangunan UMKM diyakini akan memperkuat fondasi perekonomian nasional. Bagi UMKM, yang menjadi kendala utama dalam pelaksanaan usahanya adalah bidang permodalan. Hal ini juga ditekankan oleh Majama (2017), meskipun UMKM sangat berkontribusi terhadap perekonomian sebuah negara, namun juga dihadapkan pada rendahnya kinerja dan tingkat kegagalan yang tinggi yang sering ditimbulkan karena kekurangan sumber daya seperti dana, lahan dan tenaga kerja tenaga kerja.

Sebagai tindak lanjutnya, maka PT Jasa Marga (Persero), Tbk mengeluarkan Keputusan Direksi PT Jasa Marga (Persero), Tbk. Nomor : 230/KPTS/2007 yang terakhir telah diperbaharui Nomor: 166/KTSP/2015 tentang Program Kemitraan Dengan Usaha Kecil dan Program Bina Lingkungan, yaitu untuk Program Kemitraan bersumber dari penyisihan laba Perusahaan setelah pajak maksimal sebesar $2 \%$ dan dari jasa administrasi pinjaman/ marjin/ bagi hasil, bunga deposito atau jasa giro dari dana Program Kemitraan setelah dikurangi beban operasional. Dana Program Kemitraan dalam bentuk pinjaman untuk membiayai modal kerja dan atau pembelian aktiva tetap dalam rangka meningkatkan produksi dan penjualan.

Berdasarkan kondisi permasalahan diatas, maka diperlukan identifikasi terhadap pola kemitraan BUMN saat ini dalam meningkatkan kinerja UMKM di Kota Semarang agar tumbuh dan berkembang dalam menyediakan lapangan kerja dan mengurangi tingkat kemiskinan serta memperkecil kredit macet. Oleh karena itu, penulis mengambil judul penelitian "Implementasi Peran Program Kemitraan BUMN Dengan UMKM Oleh PT Jasa Marga (Persero).

Tujuan yang akan dicapai dengan adanya penelitian ini adalah untuk mengetahui: (1) Profil 
Usaha Mitra Binaan PT Jasa Marga (Persero), Tbk Cabang Semarang di wilayah Kota Semarang tahun 2017. (2) Mekanisme penyaluran kredit pada Program Kemitraan PT Jasa Marga (Persero), Tbk Cabang Semarang kepada Usaha Mikro Kecil Menengah di Kota Semarang tahun 2017. (3) Kendala yang dihadapi selama penyaluran kredit pada Program Kemitraan PT Jasa Marga (Persero), Tbk Cabang Semarang kepada Usaha Mikro Kecil Menengah di Kota Semarang tahun 2017. (4) Efektivitas peran Program Kemitraan PT Jasa Marga (Persero), Tbk Cabang Semarang dalam meningkatkan Kinerja Usaha Mikro Kecil Menengah di Kota Semarang tahun 2017.

\section{METODE PENELITIAN}

Jenis penelitian ini adalah penggabungan antara penelitian kualitatif dan penelitian kuantitatif. Penelitian kualitatif digunakan untuk memahami fenomena yang terjadi dengan cara deskripsi dalam bentuk kata - kata dan bahasa pada suatu konteks khusus yang alamiah dan dengan memanfaatkan berbagai metode alamiah (Moleong 2007). Penelitian kuantitatif digunakan untuk mengukur efektivitas program kemitraan terhadap kinerja UMKM. Dalam penelitian ini, penulis mencoba menggambarkan peran Program Kemitraan PT Jasa Marga (Persero), Tbk Cabang
Semarang dalam pelaksanaan penyaluran kredit modal bergulir kepada UMKM dan kendala yang didapat dalam pelaksanaan penyaluran kredit modal bergulir tersebut serta efektivitas program penyaluran dana bantuan kredit modal bergulir terhadap kinerja UMKM Metode pengumpulan data merupakan tahapan yang biasanya satu metode penelitian atau lebih dipilih untuk mengumpulkan data yang diperlukan (Bungin, 2007). Metode pengumpulan data yang digunakan dalam penelitian ini adalah metode dokumentasi, metode angket dan metode wawancara.

Analisis Deskriptif untuk menggambarkan daerah atau objek penelitian. Dalam penelitian ini akan diperoleh gambaran tentang Usaha Mikro kecil Menengah yang menjadi mitra binaan PT Jasa Marga (Persero), Tbk, Cabang Semarang di wilayah Kota Semarang dan penyaluran kredit modal bergulir Program Kemitraan PT Jasa Marga (Persero), Tbk Cabang Semarang di wilayah Kota Semarang. Data yang terkumpul dari penelitian ini di analisa dengan metode analisis deskriptif untuk menjelaskan/ mendeskripsikan fenomenafenomena yang ada kaitannya dengan masalah yang diteliti. Sehingga data yang dihasilkan merupakan data deskriptif berupa kata-kata tertulis maupun lisan dari perilaku yang diamati.

Model analisis interaktif dilakukan dengan langkah - langkah seperti pada gambar berikut ini:

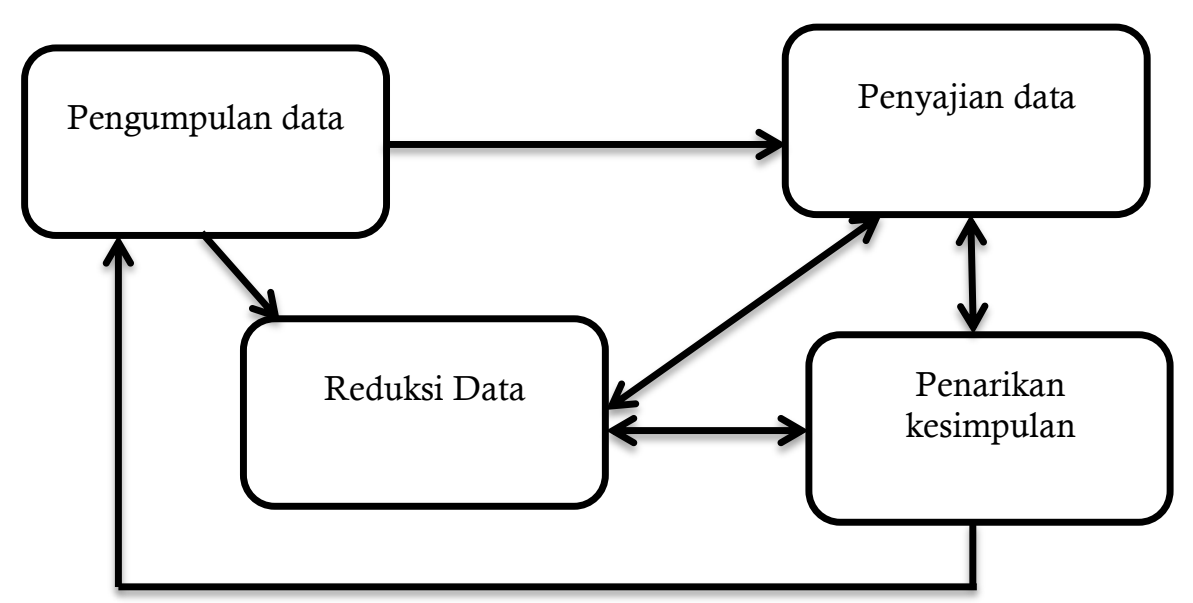

Gambar 1. Komponen Analisis Data Model Interaktif Miles dan Huberman

\section{HASIL DAN PEMBAHASAN}

Berdasarkan hasil survei, wawancara dan angket yang dilakukan mengenai Implementasi
Peran Program Kemitraan BUMN Dengan UMKM Oleh PT Jasa Marga (Persero), Tbk Cabang Semarang Untuk Meningkatkan Kinerja UMKM, dapat diketahui bahwa profil Pengusaha Mikro 
Kecil Dan Menengah di Kota Semarang yang menjadi subjek penelitian pada penelitian ini sebanyak 20 Pengusaha Mikro Kecil Dan Menengah yang berbeda - beda bidang usahanya yaitu bidang perdagangan sebanyak 11 Pengusaha Mikro Kecil Dan Menengah, bidang jasa sebanyak 7 Pengusaha Mikro Kecil Dan Menengah, dan bidang industri sebanyak 2 Pengusaha Mikro Kecil Dan Menengah. Dengan pendapatan bersih terendah perbulan $\mathrm{Rp} \quad 3.000 .000,00$ sebagai Pengusaha Mikro Kecil Dan Menengah pada usaha perdagangan sembako, dan Rp 25.000.000,00 sebagai pendapatan bersih Pengusaha Mikro Kecil Dan Menengah tertinggi pada usaha perdagangan took elektronik. Hal tersebut sesuai dengan definisi Usaha Mikro adalah perorangan atau badan usaha yang telah melakukan kegiatan usaha yang memiliki kekayaan bersih paling banyak Rp. 50.000.000,(tidak termasuk tanah dan bangunan tempat usaha) atau mempunyai penjualan/ omzet pertahun setinggi - tingginya Rp. 300.000.000,- dan milik Warga Negara Indonesia (Undang-Undang No 20 tahun 2008 tentang Usaha Mikro).

Mekanisme penyaluran kredit telah dilaksanakan sesuai dengan SK Direksi No. 230/KPTS/2007 tentang Program Kemitraan dengan Usaha Mikro Kecil Menengah dan Program Bina Lingkungan. Proses penyaluran dana bantuan kredit modal bergulir dilakukan oleh petugas PT Jasa Marga (Persero), Tbk bagian PKBL (Program Kemitraan dan Bina Lingkungan). Proses penyalurannya di awali dengan pengajuan proposal dari calon mitra binaan (Usaha Mikro Kecil Menengah) kepada pihak PT Jasa Marga (Persero), Tbk kemudian dilakukan penyeleksian dari proposal-proposal yang masuk dengan melihat kelayakannya dari berbagai aspek meliputi aspek keuangan, aspek administrasi, aspek kemanfaatan, aspek teknis, aspek pemasaran, aspek kesempatan kerja, dan aspek yuridis.

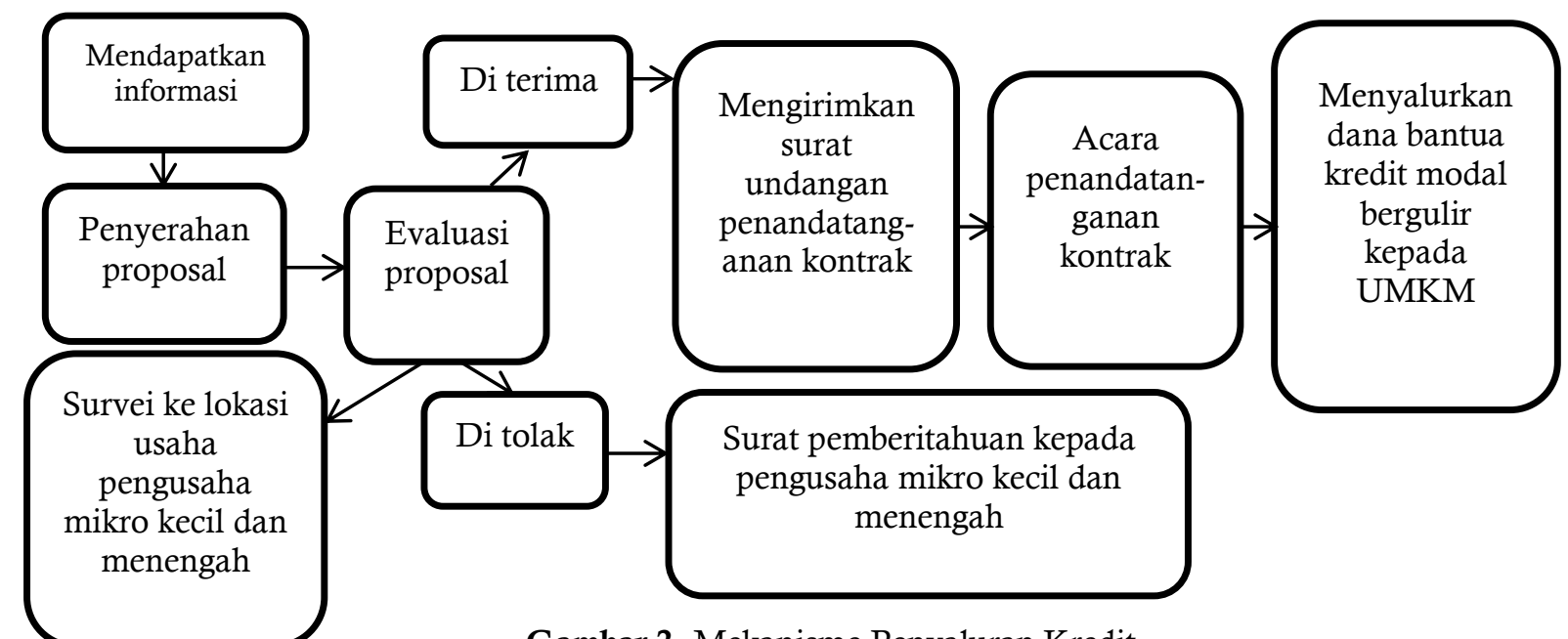

Gambar 2. Mekanisme Penyaluran Kredit

Berdasarkan tabel berikut, kenaikan penjualan bersih rata - rata perbulan sebelum dan setelah mendapatkan dan bantuan kredit modal bergulir pada 20 Pengusaha Mikro, Kecil, Dan Menengah mitra binaan PT Jasa Marga (Persero), Tbk yaitu kenaikan penjualan bersih rata - rata terendah perbulan sebesar $16,15 \%$ dan kenaikan penjualan bersih rata - rata tertinggi perbulan sebesar $126,96 \%$, dengan total kenaikan penjualan bersih rata - rata perbulan sebesar $64,75 \%$. Berikut tabel Penjualan bersih rata - rata perbulan sebelum dan setelah mendapatkan dana bantuan kredit modal bergulir mitra binaan PT Jasa Marga (Persero), Tbk Cabang Semarang. Hal ini berarti Program Kemitraan kredit modal bergulir PT Jasa Marga (Persero), Tbk Cabang Semarang kurang efektif pada total penjualan bersih rata-rata perbulan sebesar $64,75 \%$. menurut Sondang P. Siagian dalam Asiki (2010) memberikan definisi sebagai berikut: "efektivitas adalah pemanfaatan sumber daya, sarana dan prasarana dalam jumlah tertentu yang secara sadar ditetapkan sebelumnya untuk menghasilkan sejumlah barang atas jasa kegiatan yang dijalankannya. 
Efektivitas menunjukkan keberhasilan dari segi tercapai tidaknya sasaran yang telah ditetapkan. Jika hasil kegiatan semakin mendekati sasaran, berarti makin tinggi efektivitasnya. Kriteria efektivitas indikator ketepatan, sasaran, manfaat serta tujuan adalah (a) $>85 \%$ dinyatakan sangat efektif, (b) $71 \%$ - $85 \%$ dinyatakan efektif, (c) $50 \%-70 \%$ dinyatakan kurang efektif, (d) $<50 \%$ dinyatakan tidak efektif.

Tabel 1. Kenaikan Penjualan Bersih Rata - Rata Perbulan sebelum dan setelah Mendapatkan dan Bantuan Kredit Modal

\begin{tabular}{|c|c|c|c|c|}
\hline \multirow[b]{2}{*}{ No } & & Penjualan Bersih & Penjualan Bersih & \multirow[b]{2}{*}{$\begin{array}{c}\text { Kenaikan } \\
(\%)\end{array}$} \\
\hline & $\begin{array}{c}\text { Pengusaha } \\
\text { Mikro Kecil dan } \\
\text { Menengah } \\
\text { (orang) }\end{array}$ & $\begin{array}{c}\text { Sebelum } \\
\text { Mendapatkan } \\
\text { Dana Bantuan } \\
\text { Kredit Modal } \\
\text { (Rupiah) }\end{array}$ & $\begin{array}{c}\text { Setelah } \\
\text { Mendapatkan } \\
\text { Dana Bantuan } \\
\text { Kredit Modal } \\
\text { (Rupiah) }\end{array}$ & \\
\hline 1. & $\begin{array}{l}\text { KOPKAR JASA } \\
\text { PAKARTI }\end{array}$ & 189.000 .000 & 428.960 .000 & 126,96 \\
\hline 2. & M. Muhibbin & 2.800 .000 & 5.000 .000 & 78,57 \\
\hline 3. & $\begin{array}{l}\text { Dra. Siti } \\
\text { Iriantiningsih }\end{array}$ & 39.000 .000 & 45.300 .000 & 16,15 \\
\hline 4. & Rony Purwanto & 3.400 .000 & 7.000 .000 & 105,88 \\
\hline 5. & M. Makmun & 4.300 .000 & 6.700 .000 & 97,05 \\
\hline 6. & JAGO LISTRIK & 5.900 .000 & 11.000 .000 & 86,44 \\
\hline 7. & Hartini & 5.300 .000 & 8.000 .000 & 50,94 \\
\hline 8. & Suyono & 3.400 .000 & 5.500 .000 & 61,76 \\
\hline 9. & Musrikah & 3.800 .000 & 6.500 .000 & 71,05 \\
\hline 10. & Chamdan & 3.400 .000 & 5.800 .000 & 70,58 \\
\hline 11. & Budi Setiyono & 15.000 .000 & 24.000 .000 & 60 \\
\hline 12. & SOELEMAN & 13.000 .000 & 19.000 .000 & 46,15 \\
\hline 13. & Warsono & 6.100 .000 & 10.200 .000 & 67,21 \\
\hline 14. & Wahyu Fajarrini & 14.700 .000 & 18.000 .000 & 22,45 \\
\hline 15. & Ira Endrawati & 9.800 .000 & 12.200 .490 & 24,5 \\
\hline 16. & Tri Haryati & 3.400 .000 & 6.700 .000 & 97,06 \\
\hline 17. & Sarminah & 4.100 .000 & 8.500 .000 & 107,31 \\
\hline 18. & Yulianto & 4.900 .000 & 7.600 .000 & 55,10 \\
\hline 19. & $\begin{array}{l}\text { Pangestu } \\
\text { Widodo }\end{array}$ & 42.900 .000 & 50.500 .000 & 17,71 \\
\hline $\begin{array}{c}20 . \\
\text { Jum }\end{array}$ & Suharno & 8.700 .000 & 11.500 .000 & $\begin{array}{l}32,18 \\
\mathbf{1 2 9 5 , 0 5}\end{array}$ \\
\hline \multicolumn{3}{|c|}{ Total Penjualan bersih rata-rata perbulan } & & 64,75 \\
\hline
\end{tabular}

Sumber: Data Primer yang Diolah

Jumlah tunggakan tahun 2017 di Kota Semarang pada 20 Pengusaha Mikro, Kecil, Dan Menengah yaitu Rp 1.621.526,- atau sebesar 5 \%. Kualitas pinjaman dana program kemitraan dinilai berdasarkan pada ketepatan waktu pembayaran kembali pokok dan jasa administrasi pinjaman mitra binaan. Kredit modal bergulir dikatakan efektif apabila Usaha Mikro Kecil Menengah sebagai mitra binaan PT Jasa Marga (Persero).Tbk dapat mengembalikan kredit secara lancar. 


\section{SIMPULAN}

Berdasarkan hasil penelitian mengenai Implementasi Peran Program Kemitraan BUMN Dengan UMKM Oleh PT Jasa Marga (Persero), Tbk Cabang Semarang Untuk Meningkatkan

Kinerja UMKM dengan subyek penelitian sebanyak 20 Pengusaha Mikro Kecil Dan Menengah di Kota Semarang. Efektivitas dan manfaat dari penyaluran kredit pada peran Program Kemitraan dapat dirasakan baik dari pihak PT Jasa Marga (Persero), Tbk sebagai penyalur dana maupun dari pihak Usaha Mikro Kecil Menengah sebagai penerima dana bantuan kredit modal bergulir ini. Namun peran Program Kemitraan dinyatakan kurang efektif untuk meningkatkan kinerja UMKM karena pada penjualan bersih rata - rata setiap bulannya hanya mengalami kenaikan sebesar $64,75 \%$.

\section{DAFTAR PUSTAKA}

Ambarwati, Melia. 2011. Implementasi Penyaluran Kredit Modal Bergulir pada Program Kemitraan PT Jasa Marga (Persero), Tbk Cabang Semarang Kepada Usaha Kecil Menengah di Kota Semarang. UNNES.

Ansah, W. O., Cudjoe, G. A., Poku, K. 2017. The Effect of Non-Financial Support Services on Small and Medium Enterprises (SMEs) Development in a Developing Economy. International Journal of Business, Humanities and Technology, 7(1).

Asiki, Zaeni. 2010. Efektifitas Penggunaan Dana Bergulir Badan Keswadayaan Masyarakat (BKM) Proyek Penanggulangan Kemiskinan di Perkotaan (P2KP) pada Masyarakat Kecamatan Pekalongan Barat Kota Pekalongan Tahun 2008. UNNES

Bernard, Bawuah, A. S. Yakubu, M. Alhassan. 2014. The Effects of Interest Rate on Micro, Small and Medium Enterprises Financing Decision in Wa Municipality of Ghana. International Journal of Business, Humanities and Technology Vol. 4, No. 4

Bungin, Burhan.2007. Metodologi Penelitian Kualitatif Akualisasi Metodologi ke Arah Ragam Variab Kontemporer. Jakarta: PT Raja Grafindo Persada.

Keputuasan Direksi PT Jasa Marga (Persero), Tbk. Nomor: 230/KPTS/2007 Program Kemitraan dengan Usaha Kecil dan Program Bina Lingkungan.
Miles, M. B \& Huberman, M. 1992. Analisis Data Kualitatif. Terjemahan oleh Tjetjep Rohendi Rohidi. Jakarta: UI Press.

Moleong, Lexy J. 2007. Metodologi Penelitian Kualitatif (Revised Ed ). Bandung: Remaja Rosdakarya.

Mwobobia, Fridah Muriungi. 2012. Empowering of Small -Micro and Medium Enterprises (SMMEs): A Case of Botswana. Business and Management Research Vol. 1, No. 4; 2012

Peraturan Menteri Negara Badan Usaha Milik Negara Nomor PER-05/MBU/2007 Tentang Program Kemitraan Badan Usaha Milik Negara dengan Usaha Kecil dan Program Bina Lingkungan.

Sari, Dian Permana. 2008. Efektifitas Modal Bergulir Program Kemitraan dan Bina Lingkungan (PKBL) PT Pertamina Unit Pemasaran IV Semarang Terhadap Perkembangan Usaha Kecil Dan Menengah. UNNES.

Sulistyo, Heru dan Ardian. 2011. Model Optimalisasi Kemitraan Ukm (Usaha Kecil Menengah) Dan Bumn (Badan Usaha Milik Pemerintah) Melalui Program Kemitraan Dan Bina Lingkungan (Pkbl) Untuk Meningkatkan Kinerja Ukm. Dalam Riptek, Vol. 5 No. II. Hal.: 25-40 Semarang: Universitas Islam Sultan Agung.

Majama, S. N., Magang, T.I. T. 2017. Strategic Planning in Small and Medium Enterprises (SMEs): A Case Study of Botswana SMEs. Journal of Management and Strategy, 8(1).

Urfa, Vellayati Hamidah,dkk. 2013. Efektivitas Penggunaan Kredit Program Kemitraan Bumn Terhadap Kinerja Umkm. Malang: Universitas Brawijaya

Wahab, Abdul Solichin. 2004. Kebijaksanaan dari Formulasi ke Implementasi Kebijakan Negara. Jakarta: Bumi Aksara.

Yudha S,Wahyu Tri. 2008. Efektivitas Program Kemitraan dan Bina Lingkungan (PKBL) PT (Persero) Pelabuhan Indonesia III Cabang Tanjung Emas Semarang Terhadap Manajemen Pemasaran UD Unggul Karya Semarang.UNNES. 